\title{
Associations between physical activity, cardiorespiratory fitness, and obesity in Mexican children
}

\author{
Karla I Galavíz, MSc, (1) Mark S Tremblay, PhD, (2) Rachel Colley, PhD, (2) Edtna Jáuregui, PhD, (3) \\ Juan López y Taylor, MD, MSc, ${ }^{(3)}$ lan Janssen, PhD. (I)
}

\section{Galavíz KI, Tremblay MS, Colley R, Jáuregui E, López y Taylor J, Janssen I Associations between physical activity, cardiorespiratory fitness, and obesity in Mexican children. Salud Publica Mex 20 12;54:463-469.}

\begin{abstract}
Objective. To examine the independent relation of physical activity (PA) and cardiorespiratory fitness (fitness) with measures of obesity in Mexican children. Materials and methods. Children $(\mathrm{N}=193)$ in $5^{\text {th }}$ and $6^{\text {th }}$ grade from Guadalajara participated. Body mass index (BMI), sum of skinfolds (SS) and waist circumference (WC) were measured. PA was measured over four days using pedometry and fitness was measured using the 20 meter shuttle-run test. Results. Fitness and PA were negatively related to the obesity measures in boys and girls ( $r=-0.57$ to -0.64 and $r=-0.18$ to -0.23 respectively). Age adjusted significant differences in WC, BMI, and SS were observed between the lowest and highest fitness tertiles for boys and girls $(p<.0 \mathrm{I})$. Age, gender, and PA adjusted fitness explained 23 to $34 \%$ of the variance on WC $\left(r^{2}=0.23, p<.01\right)$, BMI $\left(r^{2}=0.23, p<.0 \mathrm{I}\right)$, and SS $\left(r^{2}=0.34, p<.0 \mathrm{I}\right)$. Conclusion. Fitness is a stronger correlate and better predictor of obesity than PA in this sample.
\end{abstract}

Key words: Obesity; children; physical fitness; exercise; Mexico
Galavíz KI, Tremblay MS, Colley R,

Jáuregui E, López y Taylor J, Janssen I

Asociación entre actividad física, acondicionamiento cardiorrespiratorio y obesidad en niños mexicanos. Salud Publica Mex 2012;54:463-469.

\section{Resumen}

Objetivo. Examinar la relación independiente entre actividad física (AF) y acondicionamiento cardiorrespiratorio (fitness) con obesidad en niños mexicanos. Material y métodos. Participaron 193 niños de Guadalajara en $5^{\text {to }}$ y $6^{\text {to }}$ grado de primaria. Se midieron índice de masa corporal (IMC), suma de pliegues cutáneos (SP) y circunferencia de cintura (CC). La AF se midió con podometría durante cuatro días y acondicionamiento usando la prueba de 20 metros shuttle-run. Resultados. Acondicionamiento y AF estuvieron negativamente relacionados con obesidad en niños y niñas $(r=-0.57$ a -0.64 y $r=-0.18$ a -0.23 respectivamente). Ajustando por edad, se observaron diferencias significativas en CC, IMC y $\mathrm{SP}$ entre los terciles de acondicionamiento bajo $\mathrm{y}$ alto en niños y niñas $(p<.0 \mathrm{I})$. Ajustando por edad, género y $\mathrm{AF}$, el acondicionamiento explicó de 23 a $34 \%$ de la varianza en CC $\left(r^{2}=0.23, p<.01\right), \operatorname{IMC}\left(r^{2}=0.23, p<.01\right)$ y SP $\left(r^{2}=0.34, p<.01\right)$. Conclusión. El acondicionamiento es un mejor predictor de obesidad que la AF en esta muestra.

Palabras clave: obesidad; niños; acondicionamiento físico; ejercicio; México

(I) School of Kinesiology and Health Studies, Queen's University. Kingston, ON, Canada.

(2) Children's Hospital of Eastern Ontario Research Institute. Ottawa, Ontario, Canada.

(3) Instituto de Ciencias Aplicadas a la Actividad Física y al Deporte, Universidad de Guadalajara. Guadalajara, Jalisco, México.

Received on: January II, 2012 - Accepted on: June I, 2012

Corresponding author: Karla I. Galavíz. School of Kinesiology and Health Studies, Queen's University \#28 Division Street.

Kingston, ON, Canada K7L 3N6.

E-mail: 7kgl8@queensu.ca 
$\mathrm{T}$ here is a high prevalence of overweight and obesity among children around the world. ${ }^{1}$ In Mexico, the prevalence of overweight and obesity in school-age children, as determined by body mass index (BMI), has increased at an alarming rate in the last two decades, ${ }^{2}$ reaching $26 \%$ among 5 to 11 year olds. ${ }^{3}$ This trend is concerning given the health problems that obese children are more likely to develop including elevated cardiovascular and metabolic risk factors and decreased quality of life. ${ }^{4-6}$ It has been shown that a lack of physical activity and a low cardiorespiratory fitness (hereafter referred to as fitness) are associated with total obesity ${ }^{7,8}$ and with abdominal obesity ${ }^{9,10}$ in children. What is unclear however, is which factor, fitness or physical activity, has the strongest association with obesity in children.

There is evidence that body fat in children and adolescents is associated with both physical activity, especially moderate-to-vigorous intensity activity, ${ }^{11-14}$ and with fitness. ${ }^{15,16}$ However, studies investigating these associations in a developing country such as Mexico are non-existent and findings from developed countries are mixed. Some studies have demonstrated that physical activity has a stronger association with obesity in children and adolescents than fitness, $9,17,18$ while others have demonstrated that fitness has a stronger association with obesity in children and adolescents than physical activity. ${ }^{19-21}$ Collectively, these studies demonstrate that physical activity and fitness are independently associated with obesity in children, suggesting that these variables affect adiposity through different mechanisms. Further, physical activity and fitness are different entities that should be treated separately; the former is a behavioural construct whereas the latter a set of physiological traits. ${ }^{22}$ Therefore, it is imperative to investigate the independent associations of fitness and physical activity with obesity in children, especially in Mexico where obesity levels are high and these associations are unknown, to inform future intervention strategies for this population.

Given that evidence is inconclusive and that no studies have investigated these associations in Mexican populations, the purpose of this study was to examine the independent relation of objectively measured physical activity and fitness with measures of total and abdominal obesity in Mexican children.

\section{Materials and methods}

\section{Participants}

This cross-sectional study was conducted in Guadalajara, the second most populated city in Mexico. The study sample was selected by convenience and included
193 boys and girls in grades 5 and 6 from four public elementary schools in an urban zone of Guadalajara. Two schools had a morning shift and two an afternoon shift; all of them were of a low socioeconomic status. Data were collected in November of 2009. Children's assent to participate was obtained as well as signed informed consent from their parents/caregivers. This study obtained ethics approval from the institutional ethics boards at the Civil Hospital of Guadalajara and Queen's University (Kingston, ON, Canada).

\section{Anthropometric measures}

Anthropometric measures were taken by trained anthropometrists following the protocol from the Canadian Physical Activity, Fitness, and Lifestyle Approach. ${ }^{23}$ Waist circumference was measured with a K-E anthropometric tape positioned horizontally mid-way between the bottom of the rib cage and the iliac crest. A single measure was taken at the end of a normal expiration and recorded to the nearest $0.1 \mathrm{~cm}$.

BMI was calculated by dividing children's body weight by the square of their height. Height was obtained with a Seca Road Rod 214 Portable Stadiometer and recorded to the nearest $0.5 \mathrm{~cm}$. Weight was measured with a Tanita HD-313 Digital Weight Scale to the nearest $0.1 \mathrm{~kg}$. Three skinfolds were measured using a Harpenden skinfold calliper; triceps, biceps, and medial calf, with each recorded to the nearest $0.2 \mathrm{~mm}$. Skinfolds were measured twice each and an average of these two measures was calculated. The averages from the triceps, biceps, and medial calf skinfolds were added to calculate a sum of skinfolds measure.

\section{Physical activity}

Physical activity was measured with Digiwalker Yamax SW200 pedometers over four consecutive week days. Children were provided with pedometers and instructed on how to use them. Teachers were also instructed about the use of the device and about how to demonstrate its use to children. Children were instructed to wear the pedometers during all waking hours; from when they awoke until they went to bed and repeated this process each day. Members of the research team attended the schools to provide instruction and to record step counts at the start of each school day. The average daily step count over the four day measurement period was used as the summary physical activity measure.

\section{Cardiorespiratory fitness}

The 20 meter shuttle run test ${ }^{24}$ was used to measure fitness. All testing was completed on a firm and level 
surface (concrete play area at each school). For this test, children were required to run back and forth between two lines placed 20 meters apart. A sound signal was emitted from a pre-recorded tape to dictate running speed. Frequency of the sound signals increased such that running speed increased by $0.5 \mathrm{~km} /$ hour each minute from the starting speed of $8.5 \mathrm{~km} /$ hour. The test ended when children could no longer keep pace with the sound signal. The last stage that children reached was used to predict maximal oxygen uptake $\left(\mathrm{VO}_{2}\right.$ max $)$ from the running speed corresponding to that stage $\left(\mathrm{VO}_{2} \mathrm{max}=31.025+3.238 \mathrm{X}-3.248 A+0.1536\right.$, where $X=$ the final speed and $A=$ age).

\section{Statistical analysis}

Descriptive statistical analyses were conducted to explore the characteristics of the data and to assess statistical assumptions. Independent samples t-tests were used to test for gender differences in the study variables. A one-way analysis of covariance, using Bonferroni post hoc comparisons, was used to test for differences in the obesity measures across the low, moderate, and high physical activity and fitness tertiles with age as covariate. The strength of the associations between variables was determined using Pearson correlation coefficients. Finally, hierarchical linear regression was used to determine the independent contributions of physical activity and fitness on predicting the obesity measures. Statistical significance was set at $p<.05$. All statistical analyses were performed with the Statistical Package for Social Sciences version 18 for Windows.

\section{Results}

Study participants consisted of 98 boys (51\%) and 95 girls (49\%) in grades 5 and 6 with a mean age of 11 years. As shown in table I, fitness and the three obesity measures were not significantly different across gender ( $p>$.05). Similarly, there were no significant differences in the prevalence of overweight and obesity between boys and girls as determined by BMI. Physical activity was significantly higher in boys than in girls (17996 vs. 13372 steps/day, $p<.001$ ).

The Pearson correlation coefficients (table II) indicate that fitness and physical activity were modestly correlated with each other ( $r=0.32$ boys, $r=0.26$ girls). As expected, fitness and physical activity were negatively related to the three obesity measures for both boys and girls, although some of these associations did not reach statistical significance for girls. The associations between fitness and the obesity measures $(r=-0.57$ to -0.64$)$ were stronger than the associations between physical activity and the obesity measures ( $r=-0.18$ to -0.23$)$.

To further explore the dose-response patterns of the relations, children were divided into low, moderate, and high fitness and physical activity tertiles (table III). After controlling for age, boys and girls in the moderate and high fitness groups had significantly lower waist circumference, BMI, and sum of skinfolds values in comparison to boys and girls in the low fitness groups $(p<.05)$. Furthermore, boys in the high fitness group had significantly lower sum of skinfolds values than boys in the moderate fitness group $(p<.05)$. There were no significant differences between waist circumference and

Table I

\section{Descriptive StATISTICS Of EACH StUdy VARIABLE PRESENTED SEPARATELY FOR BOYS AND GIRLS. GuAdALAJARA, 2009} Variable

$$
\begin{array}{cc}
\text { Boys } & \text { Girls } \\
n=98 & n=95
\end{array}
$$

\begin{tabular}{|c|c|c|}
\hline Age (years) & $11.1 \pm 0.8[10-13]$ & $10.8 \pm 0.7[10-13]$ \\
\hline Waist circumference $(\mathrm{cm})$ & $69.9 \pm 10.7[52.0-107.7]$ & $67.1 \pm 11.3[47.5-105.8]$ \\
\hline Body mass index $(\mathrm{kg} / \mathrm{m} 2)$ & $19.8 \pm 3.8[13.3-30.8]$ & $19.2 \pm 4.4[12.3-35.9]$ \\
\hline Sum of skinfolds (mm) & $34.0 \pm 16.2[12-74]$ & $34.7 \pm 14.8[13-77]$ \\
\hline Cardiorespiratory fitness $(\mathrm{ml} \mathrm{02} / \mathrm{kg} / \mathrm{min})$ & $47.1 \pm 4.8[37.8-59.4]$ & $46.4 \pm 4.1[37.8-55.8]$ \\
\hline Physical activity (steps/day) & $17996 \pm 5469[3265-30861]^{*}$ & $13372 \pm 4615[2598-27262]$ \\
\hline 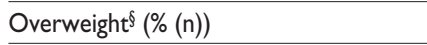 & $30.6(30)$ & $23.2(22)$ \\
\hline Obese $^{\S}(\%(n))$ & $9.2(9)$ & $8.4(8)$ \\
\hline
\end{tabular}

Mean \pm standard deviation [range]

* Significantly higher in boys than in girls, $p<.001$

$\S$ Determined through body mass index 
Table II

Pearson correlations among study Variables PRESENTED SEPARATELY FOR BOYS AND GIRLS. Guadalajara, 2009

\begin{tabular}{lccccc} 
Variables & \multicolumn{2}{c}{ Boys } & & \multicolumn{2}{c}{ Girls } \\
\cline { 2 - 3 } \cline { 6 - 7 } & $R$ & $P$ & & $R$ & $P$ \\
Fitness - Physical activity & .32 & .002 & & .26 & .013 \\
\hline Fitness - Waist circumference & -.59 & .000 & & -.57 & .000 \\
\hline Physical activity - Waist circumference & -.23 & .021 & & -.18 & .085 \\
\hline Fitness - BMI & -.57 & .000 & & -.57 & .000 \\
\hline Physical activity - BMI & -.21 & .043 & & -.20 & .053 \\
\hline Fitness - Sum of skinfolds & -.64 & .000 & & -.58 & .000 \\
\hline Physical activity - Sum of skinfolds & -.23 & .021 & & -.20 & .059
\end{tabular}

BMI between the moderate and high fitness groups. The curvilinear nature of the relation between fitness and the obesity measures is further illustrated in figure 1. Unlike the differences that were observed across fitness tertiles, the differences in waist circumference, BMI, and sum of skinfolds values across physical activity tertiles were small, and with one exception (difference in waist circumference in low and high groups in boys), were not statistically significant.

Finally, hierarchical linear regression was used to determine the independent effects of fitness and physical activity on the obesity measures. After controlling for age, gender, and physical activity, fitness accounted for $23 \%$ of the variance in waist circumference $\left(r^{2}=\right.$
$0.23, p<.01), 23 \%$ of the variance in BMI $\left(r^{2}=0.23, p\right.$ $<.01$ ), and $34 \%$ of the variance in the sum of skinfolds $\left(r^{2}=0.34, p<.01\right)$. Conversely, after controlling for age, gender, and fitness, physical activity did not account for a significant proportion of the variance on any of the obesity measures $\left(r^{2}=0.004, p>.05\right)$.

\section{Discussion}

Objectively measured physical activity and fitness were negatively associated with measures of total (BMI, sum of skinfolds) and abdominal (waist circumference) obesity in this sample of 10-13 year old Mexican children. The associations with the obesity measures were stronger and more consistent for fitness than they were for physical activity. Furthermore, when fitness and physical activity were considered in the same regression model, only fitness was a significant predictor, explaining 23 to $34 \%$ of the variance in the obesity measures.

The results of the present study of Mexican schoolchildren suggest that fitness is a stronger correlate and predictor of total and abdominal obesity than is physical activity. Although few studies have compared the strength of these associations, those existing have found similar results. For instance, within a sample of 244 children aged 7 to 10 years old from Dublin, Hussey and colleagues found that fitness and physical activity were related to waist circumference, with the stronger correlations being observed for fitness. ${ }^{20}$ In that study, fitness was assessed using the 20 meter shuttle run test and physical activity by accelerometry during four days. Similarly, Ekelund and colleagues found that fitness,

Table III

BODY FAT MEASURES ACCORDING TO TERTILES OF CARDIORESPIRATORY FITNESS AND PHYSICAL ACTIVITY WITHIN BOYS AND GiRLS. Guadalajara, 2009

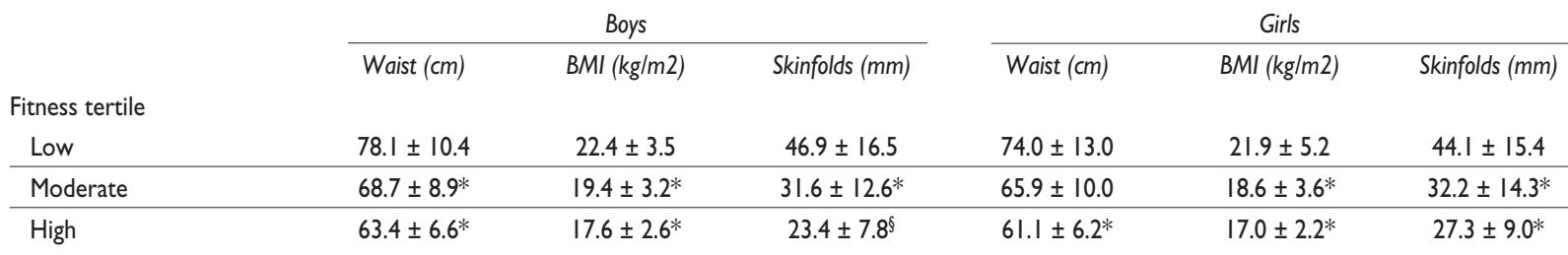

Physical activity tertile

\begin{tabular}{lcccccc} 
Low & $72.8 \pm 12.0$ & $20.7 \pm 4.6$ & $39.0 \pm 17.9$ & $68.3 \pm 11.3$ & $19.8 \pm 4.4$ & $36.1 \pm 14.5$ \\
\hline Moderate & $70.2 \pm 9.9$ & $19.9 \pm 3.4$ & $33.3 \pm 15.7$ & $66.3 \pm 13.2$ & $18.6 \pm 4.9$ & $33.4 \pm 16.9$ \\
\hline High & $64.5 \pm 9.2^{*}$ & $18.6 \pm 3.5$ & $29.6 \pm 14.3$ & $65.8 \pm 9.7$ & $18.9 \pm 3.8$ & $33.1 \pm 12.5$
\end{tabular}

Mean \pm standard deviation

* Significantly different from 'low' tertile, $p<.05$

$\S$ Significantly different from 'low' and 'moderate' tertiles, $p<.05$ 

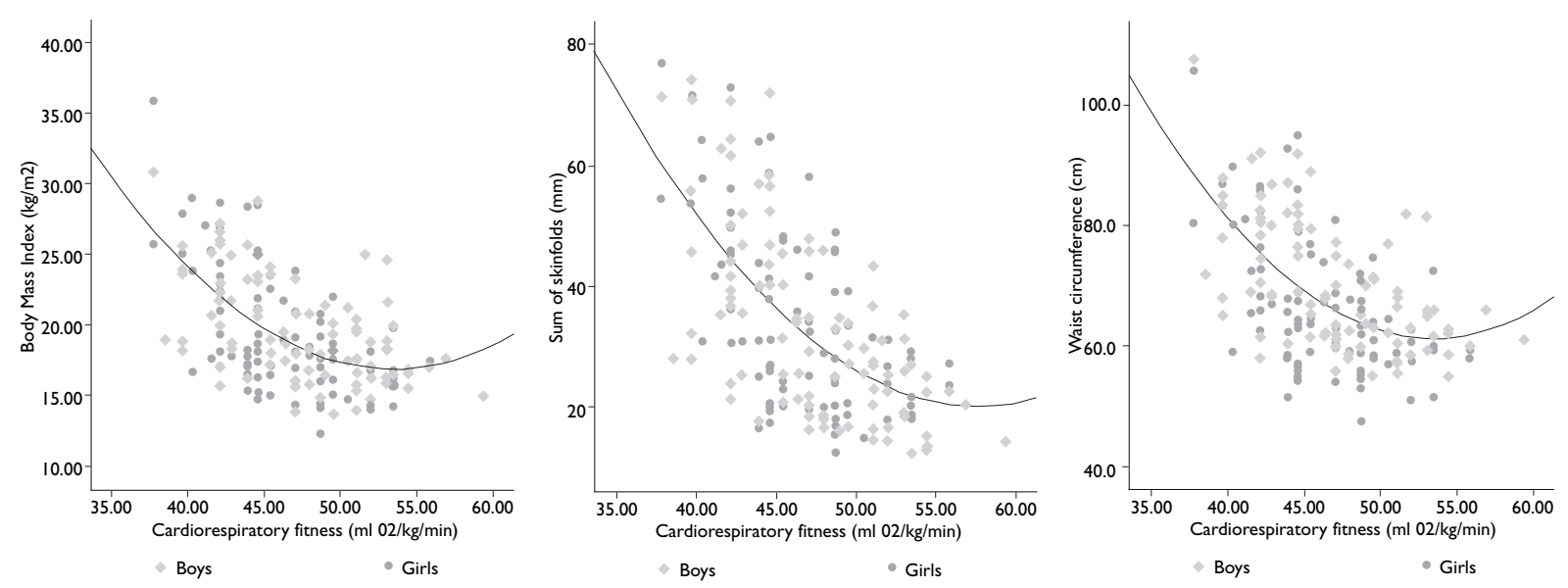

Figure I. ReLATIONSHIP BETWEen CARDIORESPIRATORY FITNESS AND THE THREE OBESITY MEASURES. DATA IS SHOWN FOR BOYS (DIAMOND SYMBOLS) AND GIRLS (CIRCLE SYMBOLS) TOGETHER. THE SCATTER PLOT ON THE LEFT SHOWS THE QUADRATIC INVERSE RELATIONSHIP BETWEEN FITNESS AND BODY MASS INDEX. THE SCATTER PLOT IN THE MIDDLE SHOWS THE QUADRATIC INVERSE RELATIONSHIP BETWEEN FITNESS AND SUM OF SKINFOLDS. THE SCATTER PLOT ON THE RIGHT SHOWS THE QUADRATIC INVERSE

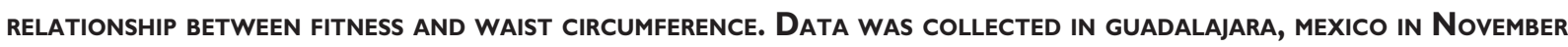
OF 2009

measured by indirect calirometry, was significantly associated with body fat estimated by skinfold thickness, whereas physical activity measured through the minuteby-minute heart rate monitoring method was not, in 82 adolescents between 14 and 15 years of age. ${ }^{19}$ Finally, Tell and Vellar found that fitness, measured during submaximal bicycle exercise, was a stronger correlate of BMI and triceps skinfold thickness than self-reported physical activity in a sample of 413 boys and 372 girls, ages 10 to 14 years. ${ }^{21}$

It has been reported that fitness is a powerful marker of health given that is associated with both total and abdominal obesity, ${ }^{25}$ which is consistent with findings presented here. The strongest association observed was that of total adiposity, followed by abdominal adiposity and BMI. Because BMI does not measure fat mass or fat distribution directly, it can misclassify individuals (e.g., a mesomorphic child may be incorrectly classified as obese). Consequently, additional obesity indicators were used in the present study which provided better estimates of adiposity.

Given that our findings differ from those that suggest that physical activity is a strong correlate of obesity in children, $9,17,18$ it is important to consider some factors that may explain our finding. First, we used pedometry to measure physical activity, which provides an estimate of children's total physical activity but no information about intensity, which may need to be of moderate- to vigorous-intensity to significantly affect body fat. $11,13,14$ Second, pedometers do not provide information about the frequency and duration of physical activity ${ }^{26}$ and given they were worn for four days only, they may not reflect children's habitual physical activity. Third, given that physical activity measures among children are typically more difficult and less precise than fitness measures, ${ }^{27}$ the observed associations between the physical activity and obesity measures in the present study may have been underestimated. Finally, fitness is partly determined by genetics ${ }^{28}$ and perhaps the genetic determinants of fitness also play an important role in obesity.

Even though our findings showed that fitness is a stronger correlate and better predictor of obesity than physical activity in Mexican children, the importance of physical activity in preventing childhood obesity should not be diminished. It has been established that physical activity has a positive influence on both fitness and fatness in children ${ }^{13,18}$ and that moderate-to vigorous-intensity physical activities are positively associated with improved fitness. ${ }^{11,17,29}$ The small association between physical activity and fitness found in the present study may be due to the inability of pedometers to capture the intensity of physical activities and that only more intense activities impact fitness. $13,18,20$ Furthermore, given that genetics account for around 40 to $50 \%$ of fitness, ${ }^{30}$ it can be assumed that the other 50 to $60 \%$ can be accounted for by environmental and 
behavioural factors that are modifiable such as physical activity. ${ }^{31}$ Therefore, directing efforts toward improving physical activity, especially in children with the poorer fitness and physical activity levels, seems to be a good avenue for battling obesity in children.

Because children spend a significant amount of their time at school, strategies for promoting physical activity and fitness among children can be implemented in this setting. The physical education class provides an opportunity to engage children in vigorous-intensity physical activities that can improve fitness. For example, physical educators could promote fitness during the class by including aerobic physical activities such as running, that are of a prolonged duration and that make children work at a moderate-to-vigorous intensity. Finally, given that fitness is associated with obesity in both boys and girls, the regular assessment of fitness in schools could help identify unfit children that are at a higher risk of obesity and its related health ailments, and remedial activity programs could be employed.

\section{Limitations}

The present study has some limitations. The sample size was small and selected by convenience, which compromises the generalizability of the findings to a broader Mexican population. Furthermore, the crosssectional design prevents us from drawing more robust conclusions on the causal relations between fitness and physical activity with obesity. Another limitation was the physical activity assessment, which, although objective, was subject to problems. Specifically, children may not have worn the pedometer properly or may have tampered with it. Moreover, pedometry measures were only obtained on weekdays, which prevented us from capturing the physical activities that children performed during the weekend. Another limitation of the pedometers used in this study is that crucial information about the intensity and frequency of physical activities was not obtained. ${ }^{26}$ Accelerometers, on the other hand, can measure both the intensity and frequency of physical activity and provide a better measure of this complex behaviour. Information about the physical activity intensity could contribute to a better understanding of the relationships among physical activity, fitness and obesity and may explain the apparent inconsistency of the present findings with some of the research discussed above. ${ }^{9,17,18}$

\section{Conclusions}

This study investigated the strength of the independent associations of physical activity and fitness with total and abdominal obesity in Mexican $5^{\text {th }}$ and $6^{\text {th }}$ graders. We conclude that fitness is a stronger correlate and better predictor of total and abdominal adiposity than is physical activity in this sample of Mexican schoolchildren. Nevertheless, the importance of physical activity in preventing obesity and promoting improved fitness should not be discounted as physical activity is the only modifiable determinant of fitness. This evidence is important given that it can help guide future public health initiatives aimed at battling childhood obesity in Mexico. Research involving larger, more representative population samples is required to further explore these associations in Mexican children.

\section{Acknowledgments}

The authors thank Ma. Teresa Acosta Álvarez, Simón Barquera, Citlali González, Mariane Héroux, Gabriela Ibarguchi, Ma. del Carmen Inojata Medina, Donna Ivimey, Juan Antonio Jiménez, Lucie Lévesque, Robert M. Malina, Luis Ortiz Hernández, Margarita Safdie, Jesús Valdés Flores, Cecilia Vallejo Ponce and Marisol Villegas Balcázar, for their involvement in organizing and teaching at the 3rd Annual CAMBIO Short Course for Obesity Researchers. We are grateful to all of the short course participants for the assistance with the data collection. The research team wishes to thank the students, teachers, administrators, staff, and parents at the schools which participated in the study in Zapopan, Jalisco: Emiliano Zapata, Cuauhtémoc, Aurelia L. Guevara, and José Ortíz Domínguez.

Declaration of conflict of interests. The authors declare that they have no conflict of interests.

\section{References}

I. Lobstein T, Baur L, Uauy R. Obesity in children and young people: a crisis in public health. Obes Rev 2004;5:4-85.

2. Bonvecchio A, Safdie M, Monterrubio E, Gust T, Villalpando S, Rivera J. Overweight and obesity trends in Mexican children 2 to 18 years of age from 1988 to 2006. Salud Publica Mex 2009;5I (4):586-594.

3. Shamah T, Villalpando S, Rivera J. Resultados de Nutrición de la ENSANUT 2006. Cuernavaca, México: Instituto Nacional de Salud Pública, 2007.

4. Chu NF, Rimm EB, Wang DJ, Liou HS, Shieh SM. Clustering of cardiovascular disease risk factors among obese schoolchildren: the Taipei Children Heart Study. Am J Clin Nutr 1998;67(6): | |4 I- | | 46.

5. Csábi G, Török K, Jeges S, Molnár D. Presence of metabolic cardiovascular syndrome in obese children. Eur J Pediatr 2000;159:91-94. 6. Friedlander SL, Larkin EK, Rosen CL, Palermo TM, Redline S. Decreased Quality of Life Associated With Obesity in School-aged Children. Arch Pediatr Adolesc Med 2003; 157(I2):I206-I2II.

7. Janssen I, Katzmarzyk PT, Boyce WF, Vereecken C, Mulvihill C, Roberts $\mathrm{C}$, et al. Comparison of overweight and obesity prevalence in 
school-aged youth from 34 countries and their relationships with physical activity and dietary patterns. Obes Rev 2005;6(2):123-132.

8. Katzmarzyk PT, Tremblay MS. Limitations of Canada's physical activity data: implications for monitoring trends. Appl Physiol Nutr Metab 2007;32(S2E):SI85-S94.

9. Dencker M, Thorsson O, Karlsson MK, Lindén C, Wollmer P, Andersen LB. Daily physical activity related to aerobic fitness and body fat in an urban sample of children. Scand J Med Sci Sports 2008; I8(6):728-735.

I0. YoonMyung K, SoJung L. Physical activity and abdominal obesity in youth. Appl Physiol Nutr Metab 2009;34(4):57I-8I.

II. Moliner UD, Ruiz JR, Ortega FB, Rey-Lopez JP, Vicente-Rodriguez G, Espana-Romero V, et al. Association of objectively assessed physical activity with total and central body fat in Spanish adolescents; The HELENA Study. Int J Obes 2009;33( I0): I I26- I I35.

I2. Moore LL, Gao D, Bradlee ML, Cupples LA, Sundarajan-Ramamurti $\mathrm{A}$, Proctor $\mathrm{MH}$, et al. Does early physical activity predict body fat change throughout childhood? Prev Med 2003;37(I):I0-17.

13. Gutin B, Yin Z, Humphries MC, Barbeau P. Relations of moderate and vigorous physical activity to fitness and fatness in adolescents. Am J Clin Nutr 2005;8I (4):746-750.

14. Abbott RA, Davies PSW. Habitual physical activity and physical activity intensity: their relation to body composition in 5.0-10.5-y-old children. Eur J Clin Nutr 2005;58(2):285-29l.

15. Klasson-Heggebø L, Andersen LB, Wennlöf AH, Sardinha LB, Harro $\mathrm{M}$, Froberg K, et al. Graded associations between cardiorespiratory fitness, fatness, and blood pressure in children and adolescents. $\mathrm{Br} J$ Sports Med 2006;40(I):25-29.

16. Nassis GP, Psarra G, Sidossis LS. Central and total adiposity are lower in overweight and obese children with high cardiorespiratory fitness. Eur J Clin Nutr 2004;59(I):|37-|4|

17. Rowlands A, Eston RG, Ingledew DK. Relationship between activity levels, aerobic fitness, and body fat in 8- to 10-yr-old children. J Appl Physiol 1999;86(4): I428-1435.

18. Ruiz JR, Rizzo NS, Hurtig-Wennlöf A, Ortega FB, Wörnberg J, Sjöström M. Relations of total physical activity and intensity to fitness and fatness in children: the European Youth Heart Study. Am J Clin Nutr 2006;84(2):299-303.

19. Ekelund U, Poortvliet E, Nilsson A, Yngve A, Holmberg A, Sjöström $M$. Physical activity in relation to aerobic fitness and body fat in I4- to I5year-old boys and girls. Eur J Appl Physiol 2001;85(3):195-201.
20. Hussey J, Bell C, Bennett K, O’Dwyer J, Gormley J. Relationship between the intensity of physical activity, inactivity, cardiorespiratory fitness and body composition in 7-10-year-old Dublin children. Br J Sports Med 2007;4I(5):3II-3I6.

2I. Tell GS, Vellar OD. Physical fitness, physical activity, and cardiovascular disease risk factors in adolescents: The Oslo youth study. Prev Med 1988; 17(I):12-24.

22. Eisenmann JC, Katzmarzyk PT, Perusse L, Tremblay A, Despres JP, Bouchard C. Aerobic fitness, body mass index, and CVD risk factors among adolescents: the Quebec family study. Int J Obes 2005;29(9): 1077-1083.

23. Canadian Society for Exercise Physiology. Canadian Physical Activity, Fitness \& Lifestyle Approach: CSEP-Health \& Fitness Program's HealthRelated Appraisal and Counselling Strategy (3rd edition). Ottawa: Canada, 2003

24. Léger LA, Mercier D, Gadoury C, Lambert J. The multistage 20 metre shuttle run test for aerobic fitness. J Sports Sci 1988;6(2):93-101.

25. Ortega FB, Ruiz JR, Castillo MJ, Sjostrom M. Physical fitness in childhood and adolescence: a powerful marker of health. Int J Obes 2008;32:I-II.

26. Trost SG. Objective Measurement of Physical Activity in Youth: Current Issues, Future Directions. Exerc Sport Sci Rev 200I;29(I):32-36.

27. Ekelund $\mathrm{U}$. Cardiorespiratory fitness, exercise capacity and physical activity in children: are we measuring the right thing? Arch Dis Child 2008; 93(6): 455-456.

28. Bouchard C. Genetics of aerobic power and capacity. In: Malina R, Bouchard C, ed. Sport and Human Genetics. Champaign, Illinois: Human Kinetics, 1986:49-88.

29. Dencker M, Thorsson O, Karlsson M, Lindén C, Svensson J, Wollmer $\mathrm{P}$, et al. Daily physical activity and its relation to aerobic fitness in children aged 8-II years. Eur J Appl Physiol 2006;96(5):587-592.

30. Bouchard C, Malina R, M. Genetics of physiological fitness and motor performance. In: Terjung R, ed. Exercise and Sport Sciences Reviews. Philadelphia: Franklin Institute Press, 1983:306-339.

31. Pate RR, Dowda M, Ross JG. Associations Between Physical Activity and Physical Fitness in American Children. Am J Dis Child 1990; 144(I0): I I23-1 I29. 